\title{
計数はかりのミスカウントの確率†
}

\author{
增 尾 竜 一*. 前田親 良* 三 船 忠 志* \\ 村上和 雄**. 谷 本 三千 秋*** \\ $*$ 大阪工業大学 大阪市旭区大宫 $5-16-1$ \\ ** (株)村上衡器慗作所 大阪市地区赤川 2-10-31 \\ *** 大和製衡(株) 明石市茶圈場町 $5-22$ \\ (昭和 47 年 10 月 9 日 受付)
}

\section{Probability of Miscounts on Counting Many Parts with Counting Scale and with Roberval Balance}

\author{
Ryūichi Masuo*, Chikayoshi Maeda*, Tadashi Minune*, \\ Kazuo Murakami** and Michiaki Tanimoto*** \\ $\left(\begin{array}{rl}* & \text { Osaka Institute of Technology, Osaka } \\ * * & \text { Murakami Kōki Co., Ltd, Osaka } \\ * * * & \text { Yamato Scale Co., Ltd Akasi }\end{array}\right)$ \\ (Received October 9, 1972)
}

There are two common methods for counting many small machine parts using a balance.

One of these consists of using a counting scale which has a large mechanical advantage $l$, and the other consists of repeatedly using a Roberval balance which has equal arm lengths. The former method counts $(l+1) N$ parts directly, and the latter method counts $2^{n} N$ parts after using the balance $n$ times, where $N$ is the initial number of parts.

The present paper is concerned with the analysis and with the comparison of the probability of miscount in these methods. The analysis is based on the assumptions that the distribution function of population of these many machine parts is always a normally distributive function which has a mean value $w$ and a standard deviation $\sigma$, and that both types of balance are always accurate.

As a result of fundamental analysis based on elementary statistics, it becomes evident that the probability of miscount is far larger in using the counting scale than in using the Roberval balance. The probability of miscount in relation to the rsesultant number of parts is presented graphically for each type of balance.

\section{1. まえがき}

機械の製造工程や，組立て工程に扮いては，ビスや ナットなどいわゆる小物の機械部品を多数取り扱から ことが多い，このような場合，部品の個数を正確には 握して扔くことは生産管理上きわめて有用である.

このように小さい部品の大きい個数を能率よく数兄 るには，これらの個々の部品の重量のばらつきが，そ

$†$ 第11 回計測自動制御学会学術講演会で発表 (昭 47.8)
の平均值と比較して比較的揃っている場合には，あら かじめ小数の部品数 $N$ 個を数光て和き，てこ比 $l$ の比 較的大きいはかりのつり合いを利用することによって $(l+1) N$ 個の計数を一度に行ならいわゆる計数ばかり が用いられることが多い:

しかしながら計数はかりは普通は計数専用に製作さ れ，他の目的に転用することが不便で，製作台数も少 なく, はかりの值段も，同一程度のひょう量で同じよ らな性能の他の形式のはかりと比較して一般に高価で 
あるから，通常の上皿天びんなぞを反覆くり返して用 いることにより計数することも一般の工場などでは広 く行なわれている.

その方法はあらかじめ計数した小数（ $N$ 個の部品を 等比上血天びんの一方の血にのせ，つり合うまで他方 の皿に部品をのせ，つり合わせた後一方の皿の部品を 他方に移し, 次はこの $2 N$ 個の部品につり合うまで, 空の皿に部品をのせるやり方で，n回つり合わせを行 なえば, $2^{n} N$ 個の部品の計数を行ならことができる.

本論文は通常の計数はかりと, 等比形の上皿天びん を用いた計数に执いて，はかりは常に正確で，ただ， はかられる部品がばらつきを持っているために生ずる ミスカウントの確率を統計学的に比較検討したもので ある.

この場合, 部品のばらつきがどのよらな形になるか 恃, その部品の製造工程等も関連して, 議論のある所 であるが，ここでは最も無難な形として，その平均值 が $w_{g}$ で，ばらつきの標準偏差が $\sigma_{g}$ の正規分布とし て計算をすすめることとした。

このようにして比較検討を行なった結果, 通常の計 数ばかりによるよりも，等比形上皿天びんを用いたほ らが，ミスカウントの確率がはるかに小さいことがわ かったので，等比形上血天びんを計数ばかりとして使 用するのに便利なような, 電子式倍数計算装置を組み こんだ，等比上四形計数ばかりを開発したので，あわ せて発表する。

\section{2. てこ比 $l$ の計数ばかりによる ミスカウントの確率}

Fig. 1 は，てこ比lの計数ばかりに和いて右小皿

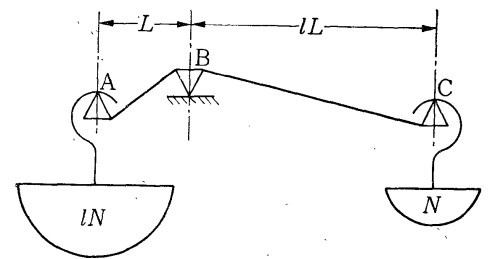

Fig. 1 Schematic diagram of counting scale

そN個の部品をのせ, 左大皿にのせた $l N$ 個の部品と つり合わせた状態を示す。

仮定によりてこは正確であるとする.

$N$ 個の部品は仮定より, その平均值が $w_{g}$ で, 標準 偏差が $\sigma_{g}$.の正規分布をした母集団から無作為注抽出 したるのであるから， $N$ 個の部品の重量として支点 C

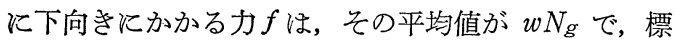

準偏差が $\sqrt{N} \sigma_{g}$ の正規分布となり，この力はてこによ って正確に $l$ 倍に拡大されてA支点で上向き働くか ら, この力 lf は, 平均值が $l w N_{g}$ で, 標準偏差が $l \sqrt{N} \sigma_{g}$ の正規分布となる.

次に左皿にかかった $l N$ 個の部品の重量 $f^{\prime}$ はその 平均值が $l w N_{g}$ と右皿沅のった部品の重量 $w N_{g}$ を $l$ 倍したものと等しくなるが，その標準偏差は $\sqrt{l N} \sigma_{g}$ となるから，てこを傾ける力 $l f-f^{\prime}$ は平均值が $O_{g}$ で標準偏差 $\sigma_{c g}$ は,

$$
\begin{aligned}
\sigma_{c} & =\sqrt{(l \sqrt{N} \sigma)^{2}+(\sqrt{l N} \sigma)^{2}} \\
& =\sqrt{l(l+1) N \sigma}
\end{aligned}
$$

となる。

この場合, 右血の $N$ 個を左血に加えると結果として 計数した部品個数 $N_{c}$ は

$$
N_{c}=(l+1) N
$$

で

$$
\sigma_{c}=\sqrt{l \cdot N_{c} \sigma}
$$

となり,てこ比 $l$, 部品総数 $N_{c}$ が大きくなるほぞ $l f-f^{\prime}$ のばらつきの標準偏差も大きくなることがわか る.

次に, Fig. 1 のA点に作用する力 $l f-f^{\prime}$ を $x_{c}$ を 特いて横軸に $x_{c}$ ，たて軸に $x_{c}$ の正規確率密度 $\phi\left(x_{c}\right)$ をとって表わすと， $x_{c}$ の平均値は 0 であるから Fig. 2 のようになり

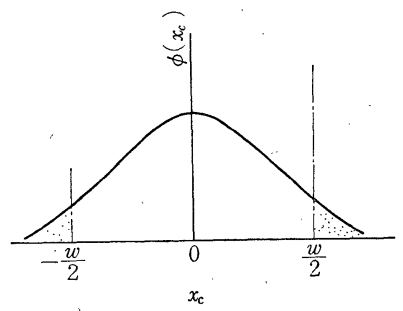

Fig. 2 Relation between $\phi\left(x_{c}\right)$ and $x_{c}$

$$
\phi\left(x_{c}\right)=\frac{e^{-x_{c}^{2} / 2 \sigma_{c}^{2}}}{\sqrt{2 \pi} \cdot \sigma_{c}}=\frac{e^{-x_{c}^{2} / 2 t N_{c} \sigma^{2}}}{\sqrt{2 \pi l N_{c}} \cdot \sigma}
$$

となる。

いまこのような $l$ 倍のてこを使用して計数を行な 万場合に, $\mathrm{A}$ 点に生ずる力の差 $x_{c}=l f-f^{\prime}$ が, 部品 1 個の重さの平均値 $w の ~ 1 / 2$ である $\pm w / 2$ を超光れ ば，左側の大きい皿に更に部品を 1 個たすか，または 1 個取りのぞいてやった注うが，より良いつり合いが 得られることとなって, 結果としてミスカウントを起 こすから，ミスカウントしないためには

$$
-\frac{w}{2}<x_{c}<\frac{w}{2}
$$

の条件を満足しなければならない。

したがって，ミスカウントしない確率は，この範囲 
の正規確率分布 $F_{c}\left(x_{c}\right)$

$$
F_{c}\left(x_{c}\right)=\frac{1}{\sqrt{2 \pi \cdot l \cdot N_{c}} \sigma} \int_{-w / 2}^{+w / 2} e^{-x_{c} 2 / 2 l \cdot N_{c} \cdot \sigma^{2}} d x_{c}
$$

で, ミスカウントする確率 $\varepsilon_{c}$ は

$$
\varepsilon_{c}=1-F_{c}\left(x_{c}\right)=\frac{2}{\sqrt{2 \pi \cdot l \cdot N_{c} \sigma}} \int_{-\infty}^{-w / 2} e^{-x_{c} 2 / 2 l \cdot N_{c} \cdot \sigma^{2}} d x_{c}
$$

で与えられる。

\section{3. 等比形のはかりを, くり返し使用した 場合のミスカウントの確率}

この方法は Fig。3 に示すようにまず最初 $N$ 個を

$1 \mathrm{st}$

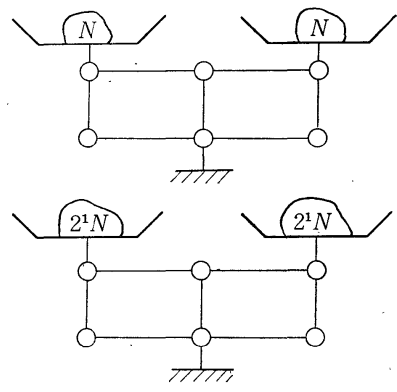

$n$th

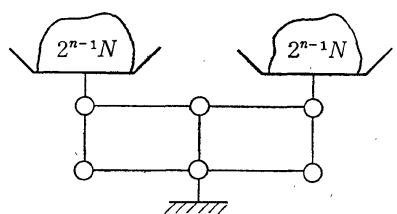

Fig. 3 Counting system by Roberval balance

数えて片方の四にのせ，これにつり合らまで，もら一 方の皿に部品をのせる。もしカウントミスがなければ 両方の四にはとれぞれ $N$ 個のっているはずだから，片 方の皿の部品をもら一方に移して $2 N$ 個とし, 2 回 目のつり合いはこの $2 N$ 個, 3 回目のつり合いは $2^{2}$ $N$ 個 $n$ 回目は $2^{n-1} N$ 個の部品同志でつり合いを取る, かくして $n$ 回目の測定まで一度もミスカウントしなけ れば，その状態での両皿の部品数の合計は $2^{n} N$ 個と なり， $n$ 回で $2^{n} N$ 個の計数を行ならことができる.

この場合，はかりは正確にできていると仮定してい るから, 右皿上の部品重量 $f_{t 1}{ }^{\prime}$ はてこにより左皿に 移され, 左皿にのった部品重量 $f_{t 1}$ とつり合うが, $f_{t 1}, f_{t 1}{ }^{\prime}$ はどちらも平均值が $w N_{g}$, 標準偏差が $\sqrt{N} \sigma_{g}$ である。

そこで $f_{t 1}$ と $f_{t 1}{ }^{\prime}$ の差を $x_{t 1}$ とすると $x_{t 1}=f_{t 1}$ $f_{t 1}{ }^{\prime}$ は平均值が $O_{g}$ で, 標準偏差が $\sigma_{t 1}=\sqrt{2 N} \sigma_{g}$ の 正規形の分布となる. いま， $N_{1}=2^{1} N, N_{2}=2^{2} N, \cdots$,
$N_{n}=2^{n} N$ として 1 回目, 2 回目, $\cdots n$ 回目のつり合い で計数される部品数を $N_{1}, N_{2}, \cdots, N_{n}$ で表わすことに すれば, $x_{t 1}, x_{t 2}, \cdots, x_{t n}$ はいずれる平均值が $O_{g}$ で, 標準偏差羊 $\sqrt{N_{1}} \sigma_{g}, \sqrt{N_{2}} \sigma_{g}, \cdots \sqrt{N_{n}}, \sigma_{g}$ の正規分布と なる。

この場合，1 回目のつり合いでミスカウントを行な わないためには，

$$
-\frac{w}{2}<x_{t 1}<\frac{w}{2}
$$

の条件を満足しなければならない。また $x_{t 1}, x_{t 2}, \cdots$, $x_{t n}$ の正規確率密度は

$$
\begin{aligned}
& \phi\left(x_{t 1}\right)=\frac{e^{-x_{t 1} 2 / 2 \cdot 21 N \sigma^{2}}}{\sqrt{2 \pi \sqrt{2^{1} N \sigma}}}=\frac{e^{-x_{t 1} 2 / 2 N_{1} \sigma^{2}}}{\sqrt{2 \pi N_{1}} \sigma} \\
& \phi\left(x_{t 2}\right)=\frac{e^{-x_{t 2} 2 / 2 \cdot 2^{2} N \sigma^{2}}}{\sqrt{2 \pi} \sqrt{2^{2} N} \sigma}=\frac{e^{-x_{t 2} 2 / 2 N_{2} \sigma^{2}}}{\sqrt{2 \pi N_{2}} \sigma} \\
& \phi\left(x_{t n}\right)=\frac{e^{-x_{t n^{2} / 2 \cdot 2^{n} N \sigma^{2}}}}{\sqrt{2 \pi} \sqrt{2^{n} N} \sigma}=\frac{e^{-x_{t n^{2} / 2 N_{n} \sigma^{2}}}}{\sqrt{2 \pi N_{n} \sigma}}
\end{aligned}
$$

となる、いま，たて軸に $x_{t \cdot n-1}, x_{t n}$ の正規確率密度 $\phi\left(x_{t \cdot n-1}\right)$ ， と $\phi\left(x_{t \cdot n}\right)$ をとって比較すると, 平均値 はともに $O_{g}$ で，標準偏差のみが $\sigma_{t \cdot n}=\sqrt{2} \sigma_{t \cdot n-1}$ と なり，皿上の個数が倍になれば，標準偏差は $\sqrt{2}$ 倍と 大きくなるためつり合わせる個数が倍々と大きくなる につれて，ミスカウントの確率が急に大きくなること がわかる (Fig. 4).

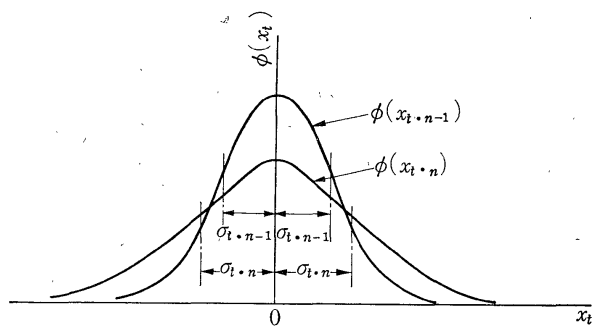

Fig. 4 Relation between $\phi\left(x_{t}\right)$ and $x_{t}$

いま, 1 回目のミスカウントの確率を $\varepsilon_{t 1}, n$ 回目 を $\varepsilon_{t \cdot n}$ とすると

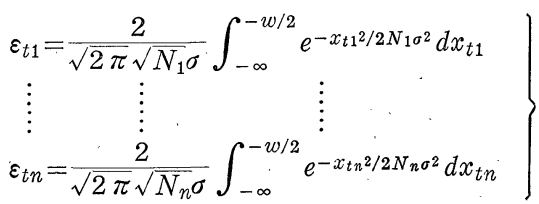

となる。圵から

$$
\varepsilon_{t 1}<\varepsilon_{t 2}<\varepsilon_{t 3} \cdots<\varepsilon_{t n}
$$

であることは明らかであり， 1 回目から $n$ 回目までの ぞれかでミスカウントする確率 $\bar{\varepsilon}_{t n}$ は 


$$
\bar{\varepsilon}_{t n}=1-\left(1-\varepsilon_{t 1}\right)\left(1-\varepsilon_{t 2}\right) \cdots\left(1-\varepsilon_{t n}\right)
$$

となる*. いま，確率の一番大きい $\varepsilon_{t n}$ が 1 と比較し てかなり小さい場合を考劣ることとすると

$$
\bar{\varepsilon}_{t n} \fallingdotseq \varepsilon_{t 1}+\varepsilon_{t 2}+\cdots+\varepsilon_{t n}
$$

となることがわかる。

\section{4. 計数ばかりと等比形天びんを反覆使用 する場合のミスカウントの確率の比較}

両者の比較は結局 (5) 式の $\varepsilon_{c}$ と（8）式 $\bar{\varepsilon}_{t n}$ を 比較すれば良い、いま，部品のでき上がり精度を平均 值 $w$ と標準偏差 $\sigma$ の比で $w / \sigma=\lambda$ と表わすことにする 之,

$$
\sigma_{c}=\sqrt{l \cdot N_{c}} \cdot \sigma, \quad \frac{w}{2}=\frac{\lambda \cdot \sigma_{c}}{2 \sqrt{l \cdot N_{c}}}
$$

これより

$$
\varepsilon_{c}=\frac{2}{\sqrt{2 \pi} \cdot \sigma_{c}} \int_{-\infty}^{-\lambda \cdot \sigma_{c} / 2 \sqrt{l \cdot N_{c}}} e^{-x_{c}{ }^{2} / 2 \sigma_{c}^{2}} d x_{c}
$$

次に $\bar{\varepsilon}_{t n}$ について考学るために， $\varepsilon_{t n}, \varepsilon_{t \cdot n-1}$ を入を用 いて表わすと，

$$
\begin{gathered}
\sigma_{t n}=\sqrt{N_{n}} \cdot \sigma, \quad \frac{w}{2}=\frac{\lambda \cdot \dot{\sigma_{t n}}}{2 \sqrt{N_{n}}} \\
\varepsilon_{t n}=\frac{2}{\sqrt{2 \pi} \sigma_{t n}} \int_{-\infty}^{-\lambda \sigma_{t n} / 2 \sqrt{N_{n}}} e^{-x x_{t n}^{2} / 2 \sigma_{t n^{2}}} d x_{t n} \\
\varepsilon_{t \cdot n-1}=\frac{2}{\sqrt{2 \pi} \sigma_{t \cdot n-1}} \int_{-\infty}^{-2^{1 / 2} \lambda \sigma_{t} \cdot n-1 / 2 \sqrt{N_{n}}} \\
\times e^{-x_{t \cdot n-1} 2 / 2 \sigma_{t} \cdot n-1^{2}} d x_{t \cdot n-1}
\end{gathered}
$$

同様にして

$$
\varepsilon_{t \cdot 1}=\frac{2}{\sqrt{2 \pi} \sigma_{t 1}} \int_{-\infty}^{-2^{n-1 / 2} \lambda \sigma_{t} \cdot 1 / 2 \sqrt{N_{n}}} e^{-x_{t \cdot 1} 2 / 2 \sigma_{t \cdot 1}{ }^{2}} d x_{t \cdot 1}
$$

となる。（10)，(11)，(12）式を比較検討してみると，

* もちろん，このほかに 1 回目から $p$-1 回目までミス カウントせず $p$ 回目 $(1 \leqq p<n-1)$ で 1 個多く（また は少なく）ミスカウントしたものが $q$ 回目 $(p<q<n)$ でこれを打消すように 1 個少なく（または多く）ミス カウントして最後には, 結果としてミスカウントして いない状態もある。この確率はたかだか

$$
\begin{aligned}
& \left(1-\varepsilon_{t 1}\right)\left(1-\varepsilon_{t 2}\right) \cdots \cdot\left(1-\varepsilon_{t p-1}\right) \cdot \frac{\varepsilon_{t p}}{2} \cdot\left(1-\varepsilon_{t p+1}\right) \cdots \\
& \cdot\left(1-\varepsilon_{t q-1}\right) \cdot \frac{\varepsilon_{t q}}{2} \cdot\left(1-\varepsilon_{t q+1}\right) \cdots \cdot\left(1-\varepsilon_{t n}\right)<\frac{\varepsilon_{t p} \cdot \varepsilon_{t q}}{4}
\end{aligned}
$$

となるから， $p$ 回目に 1 個ミスカウントして $p+1$ 回目

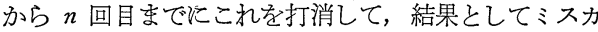
ウトが起こらない確率を $\varepsilon_{t p}{ }^{\prime}$ とすると

$$
\varepsilon_{t p}{ }^{\prime}<\frac{\varepsilon_{t p}}{2}\left(\varepsilon_{t p+1}+\varepsilon_{t p+2}+\cdots+\varepsilon_{t n}\right)
$$

となる、厳密な証明ではないが $n$ がせいぜい 10 位ま での小さい正の整数であることから， $\varepsilon_{t p}{ }^{\prime}$ が $\varepsilon_{t p}$ より 高次の微小量であることは明白で，途中で 2 個以上の ミスカウントを起こしたすのが $n$ 回目までに，これを 修正する場合はさらに高次の微小量であると考えられ るので（8）式の計算はこれらを無視した。

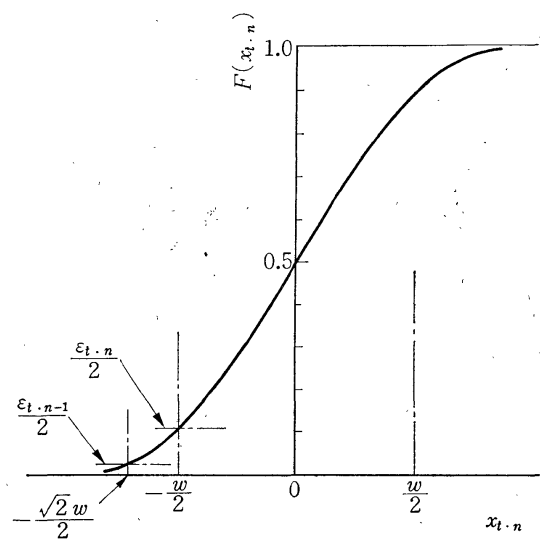

Fig. 5 Relation between $F\left(x_{t . n}\right)$ and $x_{t . n}$ 積分範囲の上限が異なるだけであるから, 横軸に $x_{t \cdot n}$ たて軸に $x_{t \cdot n}$ の正規確率分布 $F\left(x_{t \cdot n}\right)$ をとって Fig。 5 のように表わせば, $x_{t \cdot n}=-w / 2$ の $F\left(x_{t \cdot n}\right)$ が $\varepsilon_{t \cdot n}$ を $F\left(x_{t \cdot n}\right)_{x_{t n}=(-\sqrt{2} / 2) w}$ が $\varepsilon_{t \cdot n-1}$ を $F\left(x_{t \cdot n}\right)_{x_{t n}=-\left((\sqrt{2})^{2} / 2\right) w}$ が $\varepsilon_{t \cdot n-2}$ を表わし， $\varepsilon_{t \cdot n}$ が 1 に比較してかなり小さ いような場合は $\varepsilon_{t \cdot n-1}$ から $\varepsilon_{t \cdot 1}$ までの值はほとんど 無視できることがわかるから， $\varepsilon_{c}$ と $\bar{\varepsilon}_{t n}$ の比較は第 1 近似的には (9) 式の $\varepsilon_{c}$ と (10) 式の $\varepsilon_{t n}$ とを比 してもあまり違いがないことがわがる。

いま，計数ばかりによって計数した值 $N_{c}$ も，等比 形天びんで計数した值も等しい, $N_{c}=N_{n}$ の場合を考 えてみると，（9）式，(10）式に和いて積分の上限が。 $\varepsilon_{t \cdot n}$ の積分の上限は $\varepsilon_{c}$ の上限の $\sqrt{l}$ 倍の絶対值であり 計数ばかりのてこ比 $l$ は 1 に比較すればかなり大きい 数であるからら, $\varepsilon_{c}$ の硚らが $\varepsilon_{t \cdot n} よ り 大 き く ，(8)$ 式 の $\bar{\varepsilon}_{t \cdot n}$ と比較しても大きいことがわかる.

Fig. 6 は計数される部品のできあがり精度を, 部品 重量の平均值 $w$ 之, 標準偏差 $\sigma$ の比 $\lambda=w / \sigma$ で無次元 化して表わし， $\lambda=200$ の場合と， $\lambda=400$ の場合を例 にとって，計数ばかりを用いた場合と上皿天びんを用 いた場合のミ゙スカウントの確率を比較したもので, 計 数ばかりの場合は直接 1 回の計数によって得られる両 且の合計数 $N_{c}=(l+1) N$ を上且ばかりの場合は倍々 と增やしていって $n=8$ つまり 8 回目につり合った両 皿の合計数 $N_{t 8}=2^{8} N$ を横軸に，ミスカウントの確率 $\varepsilon_{c}, \bar{\varepsilon}_{t 8}$ を（8)，（9）式で計算した結果をたて軸に両 対数方眼紙上に表わしたものである. ここで，計数は かりのてこ比は $l=100,50,20$ の 3 通りについて計 算した。また，上皿ばかりはいち特う $n=8$ 回につい て表示したが (7) 式から明らかなと㧤り， $\bar{\varepsilon}_{t n} \fallingdotseq \varepsilon_{t n}$ であるから回数が変わっても，グラフ上に表われる程 度の差は生じない. 図からも明らかなと特り，入が大 きく部品の仕上がり精度が良いほどミスカウントの確 


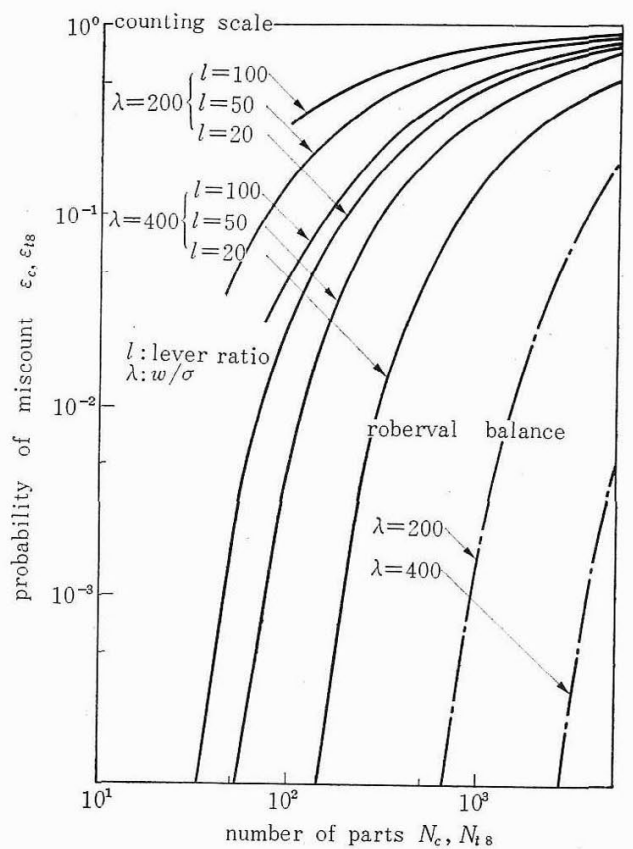

Fig. 6 Relation between probaility of miscount and number of parts

率が小さいことは言をまたないが，同一精度の部品を 計数した場合の比較に和いては, 上皿等比はかりをく り返し用いた方が，計数はかりを用いる場合よりミス カウントの確率が格段に小さく，計数ばかり間の比較 に物いては，てこ比が大きい添どミスカウントの確率 が大きいことがわかる，たと党ば， $\lambda=200$ の部品を 1000 個ほどずつはかった場合，上且等比ばかりで計 数を行なえば1個ミスカウントする割合は 1000 回に 2 回位であるが, 計数ばかりでは $l=20$ の埸合でも 2 回に 1 回ぐらいの割合でミスカウントする.

\section{5. 倍々計数装置つき等比上皿ばかりの試作}

以上の結果計数はかりに比較して，等比上皿はかり を用いたほうがはるかにミスカウントを起こしにくい ことがわかったので，最初に計数值を手動で表示すれ

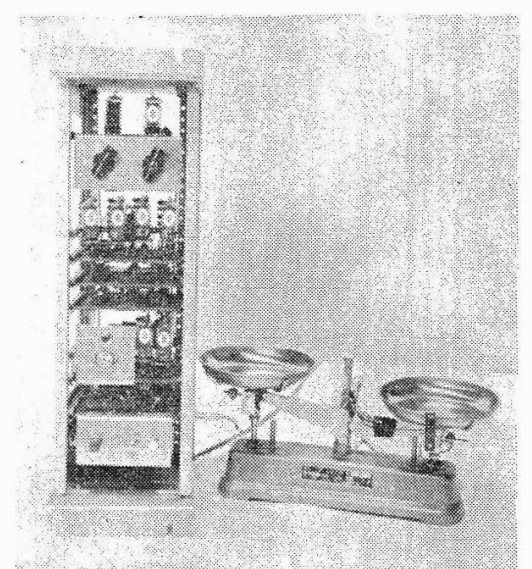

Fig. 7 Photograph of the counting apparatus

ば，1 回のつり合わせごとに表示の数值が倍々に変か。 っていくような簡単な電子回路を組んで, 通常の上血. 天びえと組み合わせた計数装置を開発した，Fig. 7 ははかり部と計数回路部の写真である。

\section{6. 結}

\section{論}

以上の結論として, 計数される部品のばらつきが, 正規分布をする大量の部品を, 計数ばかりと等比上血 天びえを用いて計数を行なった場合について解析した 結果，次の結論が得られた。

1. 一般に等比はかりをくり迈し用いた澡うが，ミ スカウントの確率ははるかに小さい.

2. 不等比はかりの場合，てこ比が大きいほぼミス カウントの確率は大きくなる。

3. 計数ばかりを用いた場合は（9）式で，等比形 上血天びん党用いた場合は（8）式と（10），(11）,

(12）式を用いてミスカウントの確率が計算でさる.

以上の結果，計数される部品の精度がわかればど の程度の個数まで, どの程度の確率で計数できるか, また計数に用いるはかりにはどの程度まで精度を考克 て設計すべきかなどが明らかとなった。 